\title{
Linguistic Politeness in the Marketing Discourse of Pushtoon Service Providers
}

\author{
* Huma Iqbal, Lecturer \\ ** Zainab Asghar, Lecturer \\ *** Nayab Waqas Khan, Lecturer (Corresponding Author)
}

\begin{abstract}
The paper aims to analyze the linguistic strategies of politeness in the transactional talk of Pushtoon Salesmen with Lahori customers. The current study assumes politeness as a tool to achieve the effect of persuasion. The data was collected randomly from the naturally occurring speech of 26 Pushtoon service providers of Auriga and Barkat Market to show an unbiased representation of the group. The recorded data was then transcribed and examined using Brown and Levinson's politeness theory. The findings of the study reveal a preference for cultural-specific address terms to soften the tone of facethreatening speech acts. Frequent use of imperatives with kinship terms, like Baji, Bhai, etc. were employed to reduce the threatening impact of direct speech. The results imply that socio-cultural values of the region is crucial to politeness. Adopting certain polite markers, relevant to the sociocultural values of the region, can compensate for the lack of language proficiency to some extent. Pushtoons service providers seem to have compensated for their lack of proficiency in Urdu by adopting socio-cultural values of Lahore. The present study contributes to the field of discourse construction where the ability of Pushtoon salesmen to use certain linguistic codes and elements to combine into utterances is demonstrated. The study is also a reflection of the pros and cons of a transactional interaction and can be used to train salesmen in marketing discourse.
\end{abstract}

Keywords: Politeness, Brown and Levinson's Theory, Persuasion, Pushtoons/Pathan

Introduction

Lahore has been a city of opportunity for the people belonging to different villages, small cities, and provinces of Pakistan. Every year, multiple families move to Lahore for job and business opportunities making Lahore a multicultural city. As a result of this migration, many Pushtoons belonging to the Khyber Pakhtunkhwa province are found in the corporate field and markets. Therefore, it is usual to encounter a Pushtoon service provider in certain markets of Lahore, such as Auriga and Barkat market. The assignment of a service provider is to convince a customer to buy his product. Service encounters are goal oriented, with goals relevant to the institution of service (Drew and Heritage, 1992). Such goal-oriented encounters require the effect of persuasion to achieve their ends. Persuasion is a purposive communicative behavior (Bostrom, 1983) aimed to intentionally change the response and behavior of the receiver by affecting his cognition because of stimuli (Petty et al., 1981). An attempt to change other feelings or viewpoint is an art that requires strategies and tactics to deal with them. According to Brown and Levinson's face work model (1987), persuasion is $\mathrm{s}$ a face threatening act as it gets the hearer to do what the speaker is inclined towards and imposes threat to the hearer's right to freedom. These illocutionary forces employed by the service provider imbalances the social equilibrium between the service provider and the customer. According to Brown and Levinson, three independent social factors determine the level of politeness: the social distance between interlocutors, relative status or power difference, and culture ranking of the imposition (Brown and Levinson, 1987). Lakeoff as cited in Aliakbari and Moalemi (2015) that politeness has been developed to minimize friction in communication. Ide $(1989$, p. 225) visions it as 'language usage associated with smooth communication', thereby emphasizing the fact that politeness

\footnotetext{
* Department of Linguistics and Communications, University of Management and Technology, Pakistan Email: huma.iqbal@umt.edu.pk

** Department of Linguistics and Communications, University of Management and Technology, Pakistan Email: zainab.asghar@umt.edu.pk

*** Department of Linguistics and Communications, University of Management and Technology, Pakistan Email: nayab.waqas@umt.edu.pk
} 
is imperative in forming efficacious relationships with people, and failure in employing politeness strategies. The current study takes the perspective of politeness as a persuasive tool to achieve their institutional goals. It analyzes the linguistic realization of politeness by Pathan salesman in an intercultural service discourse with Lahori customers, both of which belong to different culture and speak different native languages.

\section{Literature Review}

The present research utilizes Brown and Levinson Politeness model based on Face work for analyzing politeness in the speech of Pathan service provider. Facework is seen as the process in which people try to keep a balance between multiple persons' faces in social encounters (Kiyama et al.,2012). Goffman (2005) defined face as the image a person assumes he has taken during a social interaction. It is the "public self-image" that a person wants others to respect. It refers to the social sense that one expects others to recognize. Face-work is the mainstay of verbal interaction. To keep an interaction smoothly going, it is important that face of the listener and the speaker is taken into consideration. Every individual demand that his "public self-image" be respected (Goffman, 2005). Any act that contradicts one's face wants is considered as face threatening act or FTA (Brown and Levinson, 1987). The set of actions one employs to manage these face needs are described as face work. Goffman (2005) believed that interpersonal interaction involves the participants in the negotiation of face. Face is constructed discursively with others according to the line of interaction. If a speaker feels that he is performing a face-threatening act, he mitigates the threat according to his/her own individual disposition or the situational context. In other words, the speaker uses certain politeness strategies to reduce the impact of this face-threatening act. These politeness strategies allow the participants to maintain an atmosphere of relative harmony in instances of any disagreement.

Brown \& Levinson (1987) determined strategies for constructing and managing forms of harmonious social interaction. According to this model, an individual possesses either positive or negative face. A positive face requires expression of appreciation and emphasizes closeness between the interlocutors. It is to fulfil one's need to be accepted and feel connected through common goals. Solidarity strategies that express common grounds with the hearer are generally associated with the positive face wants of a speaker. In group identity markers, jokes, humor, casualness, expressing ideas as needs and wishes are all meant to create a feeling of solidarity. In-group markers claim common grounds with others. It is to speak as one of the members of the community, softening the weight of FTA. Joke is an in-group marker since it requires a prior knowledge of the image, creating and strengthening group membership (Diamond, 1996, Brown \& Levinson, 1987).

Negative face of person is the need to be independent in his actions and not to be imposed on by others (Yule, 1996). Redressive actions focus on the hearer's want of freedom of actions to minimize the effect of that imposition that FTA creates. Creating distance between the interactants by offering an apology (for instance, "Main apka ziadha waqt nai loon ga, per....."), being indirect and softening requests (for e.g. main soch raha tha, agar ap.....) are some of the different negativepoliteness strategies used by the speaker $(1987$, p.131). Others may include being indirect, using hedges, questions, reducing imposition, giving deference, apologizing, impersonalizing, nominalizing (Brown and Levinson, 1987).Use of syntactic construction implying requirements, obligation and necessity, passive voice, impersonal verbs, fewer personal pronouns and reference to personal needs and wishes, an increase in impersonal, agent less sentences mark deference strategies. Such strategies are characterized as negative politeness strategies (Brown and Levinson, 1978).

One of the politest ways to communicate FTA is to act "off record". Such "off record" acts leave the interpretation of a speech act open to question. Such acts have more than one communicative intention, leaving it to the addressee to interpret it as he thinks. Fifteen 'off-record' strategies were identified by in Brown and Levinson's politeness theory. It is important to violate Grice's maxims of efficient communication to communicate a face threatening act 'off record' to trigger the hearer to look for the intended meaning by the speaker. Fifteen 'off record' strategies have been identified by Brown and Levinson (1987, p. 217): Understatement, use of tautology, presupposition, giving hints, overstatement, give association clues, use of contradictions, being ironic, over-generalization, use of rhetorical questions, being ambiguous, being vague, use of metaphors, displace $\mathrm{H}$, be incomplete, use ellipsis. Requests, warning, advice, disagreement in an interaction are some of acts that cause a threat to others face. The gravity of risk involved in performing FTA is determined by the cumulative effect of the relative 'power' between the addresser and the addressee, 
the social distance between them, absolute 'ranking' of imposition in the particular culture (1987, p.74). A review of the literature on the topic of politeness strategies found that a growing body of literature has investigated politeness in different fields. It has been studied widely in advertisement (e.g., Danilina, Kizyan \& Maksimova, 2019; Khalik\& Supatmiwati, 2019), workplace discourse, like doctor-patient interactions (eg., Iragiliati, 2012; Odebumni, 2013), in legal language of courtroom discourse (Tracy, 2017; Archer,2017), in teacher-students classroom interaction (eg., Rustandi,2018; Rahayuningsih \& Fitriati, 2020;), and in the area of corporate settings (Kong, 1998; Pan, 2000; Kerbrat-Orecchioni, 2006). In the recent years, politeness in corporate setting has been further developed to politeness by service providers (eg., Lin, 2005; Kerbat- Orecchioni,2006; Traverso, 2006; Liu, 2009; Reiter \& Bou-Franch, 2017; Ativie, 2020).

Politeness is the base of any social interaction. It is a socio-cultural phenomenon because it is based upon the social norms and social values of the specific community (Yasmeen, Jabeen \& Aatika 2014). Politeness, in Pakistani context, has been studied with respect to marital relations (Khokhar,2017); in the language of Pakistani politicians (Yasmeen, Jabeen \& Aatika 2014); with reference to social hierarchies (Kousar,2015), etc., but no study, to the best of my knowledge, has been conducted in the corporate setting till date.

Thus, in this study, we aim to investigate different linguistic politeness strategies employed by Pathan service providers, during negotiation, to persuade Lahori customers to buy their product. The Pushtoons belong to Khyber Pakhtunkhwa, a province with the most distinctive culture in Pakistan (Moshadi \& Amjad, 2011). Since the negotiation takes place between Pushtoons service providers and Lahori customers, the sales communication is necessitated to occur in Urdu Language, the national language of Pakistan. Pushtoon recognize strongly with their mother tongue (provincial language) and prefer their provincial identity and language over national language. As a result, people are not fluent in their national language. With individuals speaking two different languages, the ways to do politeness becomes more complicated (Liu, 2009). In such cases, the sales encounter is carried out in the national language, i.e., Urdu, a situation common in Lahore, a multicultural and multilingual hub in Pakistan. Liu (2009) who had studied such complicated interaction between Chinese and non-Chinese sales provider and customers discovered that the salesperson, i.e. the interlocutor with lower language proficiency, tended to use minimal responses to signal positive politeness to the customer, perhaps due to limited language choices. Considering the situational context, the present research addresses the following research questions:

a) What are the frequently employed politeness strategies used by Pathan salesmen in their service encounter with Lahori customer?

b) How do the Pushtoon service providers with lower language proficiency manage to compensate for their limited linguistic repertoire to redress the face needs?

\section{Methodology}

\section{Data Collection}

The current research takes on a descriptive qualitative design; keeping in consideration the nature of research and the form of data collected. The data consist of a corpus of audio-recorded service encounters collected from Pushtoon service providers in communication with Lahori customers. The participants for this study consist of male Pushtoon service providers working in Lahore. During the data collection process, twenty-six Pushtoon salespersons' conversations with customers were recorded for around nine hours, in the evening, on weekends. The participants for the study were selected through simple random sampling to show an unbiased representation of the group. The choice of Pushtoon participants and the situational context of persuasion were controlled by opting for markets like Auriga and Barkat that are populated by Pathan salesmen. The data collected was transcribed and coded.

\section{Procedure}

The data were analyzed using a deducted approach to content analysis based on Brown and Levinson's theory of politeness (1987). Content Analysis is a research method used to analyze written, verbal, or visual communication artifacts. It is concerned with the meanings and intentions of the text. This research method is used to analyze social phenomenon conceptually without invasion, in contrast, to stimulating social experiences or collection of data through a survey. Move was taken to be the unit of analysis. The linguistic devices for politeness were codified using 'move' as the unit of analysis. Moves are the structural categories in which a turn can be divided, and which identify a new 
function in the discourse of the speaker (Perez de Ayala,2001). For instance, the following response given by a shopkeeper in the present study will be considered as a move:

When the customer expressed concern regarding the quality of product, the shopkeeper responded in these words:

Shopkeeper: Tension na lo, jo bhi ho wapis karo, Yeh dukaan hai, kharab ho, wapis laol/ buhat pyari shirt hai.

(Do not stress, return anything it's a shop, in case anything is wrong // It's a beautiful shirt).

In this quote, the shopkeeper uses two rhetoric moves in one turn. The first one was a solidarity strategy i.e. the 'willingness to attend to the customer's concern' where he asked his customer to return the product in case there is some flaw. The second move was a compliment that he gives to the product. For clarity, each move has been separated by a //.

The study roughly quantifies the politeness strategies using move as the unit of analysis and places each linguistic device as a sub-category to Brown and Levinson's politeness theory. Once categorized, qualitative analysis for common patterns, themes, intentionality, and implications of verbal political effectiveness is conducted. The following points were considered during analysis:

- The socio-cultural background, the situational context, and the sequential analysis of interaction.

- The researcher's communicative competence as a speaker of Urdu and a member of the speech community is utilized to analyze and interpret utterances.

- Inferences were made based on the situational, cultural, social contexts.

- Previous utterances in the discourse were also be taken into consideration.

\section{Data Analysis}

The coded data revealed five strategies for positive politeness and three strategies for negative politeness. This is seen in Table 1 below. The frequency distribution of these strategies can also be found in the Table No. 1. It shows that in positive strategy, the use of in-group identity markers to enhance solidarity is the most frequently used strategy (49\%), followed by the need to notice and show concern strategy (18\%) The least frequent positive strategy used is to act logical and rational $(4 \%)$. For negative politeness, three negative politeness strategies are identified with the most frequent strategy being deference strategies (23\%). In this paper, I will provide a detailed analysis of the dominant themes.

\begin{tabular}{lll}
\multicolumn{3}{l}{ Table No. 1. Frequency Distribution of Politeness Strategies } \\
\hline Solidarity strategies & Frequency of use & $\%$ \\
\hline Notices and shows concern & 18 & $18 \%$ \\
Offers promise & 17 & $17 \%$ \\
In group membership & 49 & $49.49 \%$ \\
Seeks agreement & 11 & $11 \%$ \\
Acts logical and rational & 4 & $4 \%$ \\
Total & 99 & 100 \\
Deference strategies & Frequency of use & Percentage \% \\
Indirect strategies & 15 & $40 \%$ \\
Reducing imposition & 5 & $13 \%$ \\
Giving deference & 17 & $46 \%$ \\
Total & 37 & $100 \%$ \\
\hline
\end{tabular}

The use of solidarity strategy emerged to be the dominant theme during analysis. The Pathan service providers were found to be using solidarity strategies frequently to trigger a change in attitude.

\section{Expression of Solidarity}

Solidarity utterances are a kind of metaphorical extension of intimacy. It is meant to imply common ground and the sharing of wants even between strangers. In the data that were collected, almost seventeen out of twenty used solidarity strategy in their persuasive discourse. The linguistic realization of solidarity reflected in the salesman's speech has been analyzed considering the situational and local context of persuasive discourse.

\section{Use of kinship Codes}

Belonging markers are the most common politeness strategy discovered in the discourse of Pathan shopkeepers with Lahori customers. In group markers, like 'baji' (sister), 'behan' (sister), 'gudriya' 
(little girl), for female customers and 'bhaijan' (brother) for male customers were observed. According to Brown and Levinson (1987), these markers have positive politeness functions.

100 rupee ki koi raqam nai hai, itna tu bhai ko bolne ka haqq banta hai. Doctor ke pass jao tu kitni fees mangta hai, pata hai sirf bolneka

(100 rupees is no money. A brother has that much right to say. When you go to the doctor, he charges you so much just for consultation).

The shopkeeper in this example, quite obviously reduces the distance between himself and the customer by constructing a kinship relationship with the customer so that he could speak freely and demand as much as he wants.

Baji, do saal se bhaich raha hoon.Aj tak kissi ki shikayat nai ayi.

(Sister, I have been selling it for the past two years. I did not receive any complaints till date).

Gudriya, keliyelai lain (Buy it for the little girl).

The degree of threat attached to behavior is influenced by the level of intimacy in a relationship. Lahoris believe in cohesiveness, and prioritize group over individual selves. When the customer asked for a price reduction, the shopkeeper replied with a direct 'No' but later mitigated the effects of direct refusal with "Baji", embedded in the communicative context.

Nai, baji.

(No, sister)

O meri behan, kharab nai hota. Le lo sahi

(My sister, it will not deteriorate. Do buy it)

The phrase "kharab nai hota" if uttered without "baji" would have been considered rude and direct disagreement, considering the constrained relationship of the customer with the salesman. Similarly, the imperative "le lo sahi" would have been threatening if it had been uttered without address the term "my sister" in the surrounding linguistic context.

The salesman's expression of disagreement by using the belonging marker "baji" acts as a polite marker.

Baji, hazaar main saadha kapra bhi nai ata, suit ki tu baat hi choro.

(Sister, you cannot buy a simple cloth in thousand rupees, let alone a suit)

These hedges (kinship terms) were embedded to reduce the impact of certain stress rising situations to establish a long-term relationship with the customers. Prosodic ally, a softening in the tone of the shopkeeper with the word "baji" was observed. In some cases, a rise of tone was observed in imposing statements, but the tone softened with the word "baji or bhaijan". A scrutinize examination of the linguistic context revealed that the use of kinship address terms increased with the use of imperatives or disagreement.

For instance, "baji, 800 ka yeh hai hi nai." Imperatives include acts like order, assertion, insistence, direct refusal.

Baji, bazaar check karo

(sister, survey the market)

\section{Express Concern for the Customers}

The 'show of concern' is the second most frequently used strategy meant to connect with others. Through this strategy, the shopkeeper tried to establish common ground with the customer to make him feel that he can identify his perspective and is sensitive to it. Some of the extracts from the salesmen's speech have been discussed below:

The shopkeeper notices and attends to the customer's concern regarding the variety of designs in a single colour dress in the following words

Iss colour main koi aur dikha doon?

(Should I show you some other (design) in this colour?)

Yeh dekha doon? Buhat acha design hai.

(Should I show this? It is an excellent design).

On the customer's expression of concern regarding the deterioration of fabric after a wash, the salesman responds:

Jis tarah marzi wash karain...koi bhi masla ho paise wapis. Net ki hamari guarantee hai. Jis tarah marzi wash karain.

(Wash as you like it. In case of any problem return it. We give a guarantee of the quality of our net. Wash as you like it). 
The use of syntactic construction like "Jis tarah marzi istemaal karain" twice, shows the importance the salesman gives to the customer's concern. Repetition of words shows the salesman's effort to achieve "emotional agreement" with the utterance (Brown and Levinson, 1987, p.113)

\section{Seek Agreement}

In certain cases, the service providers sought the customer's agreement to attend to the customer's wants and needs.

Kapra dekhain, achi cheez hai..bilkul bareek aur yeh dekhain.100 percent cotton.

(Check the cloth, it is of good quality. The cloth is delicate and check it is 100 percent cotton).

Kapra dekhain Zara, malai ki tarah maal hai.Check karain,baji.

(Check the fabric, it is a soft cloth, Check the cloth, sister).

Yeh lain stuff check karain zara. Bilkul pehane main soft, garmi nahi lagegi.

(Take this, check the fabric. It is absolutely soft, you will not feel hot).

Consultative phrases like "check karain"and"dekhain zara", "dekhadoon"in the following examples imply that the salesman is trying to seek the agreement of the customer.

In the following instances, the speaker employs the implicit device of 'interrogatives' to seek the agreement of the shopkeeper.

Kitne plantain karni hain baji?

(How many plates do you want to buy, sister?)

Yeh baji pasand hai apko, laina nai apne?

(Do you like it, sister? Do you not want to buy it?)

However, in example $4 \mathrm{~b}$, the negating element "lainanaiapne" in making a request is way to convey some degree of "polite pessimism" (1978, p.179).

\section{Offer Promise and Guarantee}

To strengthen his conviction, the shopkeeper offers the customer all kinds of promise and guarantee. Offering promise is a positive politeness. The following are instances of offering promise in the speech of the shopkeepers.

The salesman to persuade the customer to buy his product offers him a promise.

Inshallah, behan leke jayage, dobara bhi lene ayainge.

(God permits, sister, if you buy it, you will visit again to buy from me).

The shopkeeper gives a guarantee of the quality of the net.

Net ki hamari guarantee hai, jis tarah marzi wash karain.

(We give you the guarantee of the quality of net. Use the way you like it).

In the following instance, the customer expressed his doubt regarding the type of fabric.

Customer: Yeh rashmi lagraha hai?

(This seems to be silk?)

Shopkeeper: Reshmi howa, tou 50000 jurmana, yeh zuban hai meri.

(In case it turns out to be silk, 50000 will be paid as a penalty, this is my word).

Baji, main aap se kya kehraha hoon, imandari se, aap mere paas dobara mangne aoge.Eik dafa nai, teen dafa laike jaoge.

(Sister, I am telling you, believe me, you will visit me again. Not once, three times you'll come to buy).

Explicit phrases like "zuban hai meri" and "dobra bhi leneay ainge",Immandari se". "Net ki hamari guarantee hai" express promise and guarantee in the speech of shopkeepers.

Deference Strategies

Indirect strategies, deference strategy, reducing imposition and Hedges (discussed under solidarity strategy) are some of the frequently employed negative face strategies. They were not as prominent as compared to solidarity strategies.

\section{Indirect Strategies}

According to Brown and Levinson (1987), if the intentions of a communicative act is ambiguous or not clear and can contain two or more interpretations to an act, it is called an off record strategy (p. 211). These off record utterances have been placed under indirect strategies as suggested by Brown and Levinson. When the customer told him that he would take a round of the market and then get back to him for buying the dress, the salesman responded in the following way:

$\rightarrow$ Customer ka kuch pata nai, kabhi 8 le kabhi 6 le ..

(You never know, a customer may buy eight or six at a time) 
The shopkeeper requests him/her indirectly (hint) to buy the product instantly with an overstatement that the other customer may buy 8 or 6 at a time and that s/he may not get it later.

$\rightarrow$ Subah se 25 -30 kurte bachay hain, saare khatam hogaye hain, thoray hi rahgaye hain.

(Since morning, I have sold 25 to 30 shirts, almost sold all, left with few.)

On another customer's interest in surveying the whole market, before buying the product, the shopkeeper responds:

$\rightarrow$ yehi cheez milagi apko pooray bazaar main...

(You will find similar product in the whole market)

The salesman, in the above quotation, warns the customer that he will find similar product in the whole market by over generalizing his product.

\section{Reducing Imposition}

The Pathan shopkeepers were found constantly insisting the customers to buy their product. When the salesman was persuading the customer to buy utensils from him:

$\rightarrow$ Agar lenahai, le lo acha cheez hai.

(If you want to buy, then buy it.It is a good thing.)

$\rightarrow$ Phir bhi koi faraq ho, paisay wapis.

(In case, there is a discrepancy, money will be returned.)

$\rightarrow$ Agar koi masla ho,paisay wapis.

(If you have any problem, money will be returned).

The "if condition" embedded in the speech of the salesman reduced the imposition to the customer.

This implicit strategy has been rarely used as compared to other linguistic devices.

\section{Giving Deference}

Giving deference is strategy meant to maintain respectful distance between the customer and the shopkeeper. The salesmen were found using "aap" as a sign of respect for the customers.

$\rightarrow$ Phir bhi ap lelain baji, two sets 2500 main dainge aapko.

(Ok then, sister.We will give you two sets (dishes) in 2500)

$\rightarrow$ Baji, aap lejao, bazaar check karo.

(Sister, you can take it and survey the market.)

Considering the socio-cultural context of Lahore, aap or apne indicates deference towards the other person. The use of this word is a gesture of respect. This is meant to create distance as too much of informality could lead to careless and absent-minded talk and in turn create ill-feelings.

In one of the customer-salesman interaction, when the salesman had realized that the customer did not have any intention to buy his product and was just there to survey, he turned rude and changed from the pronoun "aap" to "tumne". This instance is a clear indication of how deference is a strategy to persuade customers.

$\rightarrow$ Lena hai tumne? Lenay hain tumne tu bataonga, nai lanay tu kyun bataon?

Do you want to buy? I will tell you only if you want to buy, if you do not want to buy, why should I tell you?

"Tumne" in Urdu language is an informal reference to somebody and is considered rude when used between strangers. The shopkeeper, on realizing that the customer did not want to buy the product changed from "apne" to "tumne" and simultaneously refused to attend to the customer's need with words "nai lanay tu kyun bataon?"

$\rightarrow$ Ajain, Ajain, idher ajain, 1000 rupee main sale hai.

(come, come, come here, sale in thousand rupees.)

"ain" is a particle which when attached to verbs shows deference to the person who is asked to do a particular action for instance "ajain" (asking someone to come with respect).

\section{On -record Strategies}

Although the salesmen were found using many threatening and direct acts, discussed earlier, they mitigated its effect with the belonging marker, "baji". Those who used on record utterances did not sound rude or impolite to the customer. The reason could be explained in terms of the local context.

\section{Imperative}

(Leave survey and listen!)

Insistence

$\rightarrow$ Le lo, sahi hai.

(Take it, it is okay.) 
Nevertheless, compared to solidarity and deference strategies, the bald-on-record strategy was not used frequently by the salespersons. 19 out of 26 did not use bald on record strategy at all.

\section{Discussion}

The study unveils the frequent use of kinship address terms as a communication strategy to persuade. These cultural linguistic kinship codes were used as polite markers to build a relationship and to reduce the impact of a threatening act (hedges). Pathan salesmen were found to use imperatives frequently, reducing its impact with honorific addresses. The face-threatening speech acts of suggestion, direct refusal, and suggestion were softened with the linguistic kinship codes. The frequent use of belonging markers along with imperatives and direct speech implies towards the following reasons, with reference to the global and the local context.

The employment of address terms could be considered as a linguistic code relevant to the positive culture of Lahore .Utilizing the cultural values of Lahoris, i.e. collectivism, they try to use it to their benefit to emotionally charge customers to buy their product. Lahoris believe in collectivism where establishing common grounds is considered more polite than infringing upon other's independence. Ali et al. (2018) believe that Pakistan promotes collectivism culture and discourage individualism.

The language preference manifested in interaction by the participants establishes social identities for both the speaker and others related to the interaction. Owing to the harsh and rigid environment of Khyber Pakhtunkhwa, imperatives acts could be explained in terms of their rigid and autonomous nature. However, in their encounter with the Lahori customer, the salesmen may have attempted to be pragmatically polite by consciously paying attention to linguistic forms that exhibit the positive culture specific preferences of Lahoris since speakers who do not use pragmatically appropriate language run the risk of appearing uncooperative or rude. As stated by Kecskes (2013), culturally variant communicator in service encounters relies on prior knowledge and culture of a relatively definable speech community which is privatized by an individual belonging to that speech community (p.100).

The frequent use of fictitious kinship softens the tone of the force of the illocutionary acts and do not change or contribute to the literal meaning of a sentence. It reduces the impact of the Pathan's authoritative nature and imperatives, reflected in their communication. The finding could very well be justified by Ogiermann (2009) who reinforces that imperatives are generally associated with orders but they can also be used as a polite request if their illocutionary force is softened with intonation, personal pronouns, address forms or modal articles (p.159-160).

Lack of politeness variation can be explained in terms of lack of language proficiency A striking difference between the use of belonging markers and other positive strategies infers that the Pathan service providers possess the socio pragmatic knowledge required for effective communication in Lahore but lack linguistic components to express them efficiently. Lack of proficiency in Urdu language makes their use of other forms politeness devices, except kinship terms, challenging.

\section{Conclusion}

The research aims to investigate the linguistic politeness strategies employed by Pushtoon service providers to achieve the effect of persuasion. The findings reveal the frequent use of culturally specific fictitious address terms, defined by the sociocultural values of the region. Lack of variation in the employment of politeness strategies implies a lack of proficiency which was compensated with frequent use of fictitious kinship terms. Hence, it can be understood that pragmatic knowledge of the socio-cultural values of the region can overcome the lack of proficiency in the language. There are certain limitations to the study. The research does not consider the individual disposition of the salesmen to analyze the social differences like education, background and the length of their stay in Lahore that may affect the choice of linguistic forms to be verbally political in their encounter with customers.

Since the findings of the study concentrates on the frequency of the use of culturally specific kinship codes in Urdu language, it can also be researched if similar codes are employed by Pathans in 
Pushto too. A comparative study on politeness strategies of Pathan and Punjabi service providers of Lahore would be an interesting study to determine regional variations in linguistically and culturally diversified city like Lahore. Such researches would further strengthen the scope of the present research, with respect to language and culture.

\section{References}

Ali, R., Khurshid, K., Shahzad, A., Hussain, I., \& Bakar, Z. A. (2018). Nature of Conceptions of Learning in a Collectivistic Society: A qualitative case study of Pakistan. Eurasia Journal of Mathematics, Science and Technology Education, 14(4), 1175-1187.

Archer, D. (2017). (Im) politeness in Legal Settings. In the Palgrave Handbook of Linguistic (Im) politeness (pp. 713-737). Palgrave Macmillan, London.

Ativie, K. (2020). Politeness in service encounters: A study of Nigerian Pidgin. Awake Journal of English Language and Literary Studies, 7(194-207).

Brown, P., \& Levinson, S. C. (1987). Politeness: Some universals in language usage. Cambridge University Press.

Danilina, E. A., Kizyan, E. E., \& Maksimova, D. S. (2019). Euphemisms in advertising discourse: Putting on a positive face and maintaining speech etiquette. Training Language and Culture, $3(1), 8-22$.

Diamond, J. (1996). Status and power in verbal interaction. A study of discourse in a close-knit social network. Pragmatics \& beyond. New series, 40.

Drew, P., \& Heritage, J. (1992).Talk at work: Interaction in institutional settings. Cambridge University Press.

Goffman, E. (2005). Interaction ritual: Essays in face to face behavior. Aldine Transaction.

Ide, S. (1989). Formal forms and discernment: Two neglected aspects of universals of linguistic politeness. Multilingua-Journal of Cross-cultural and Interlanguage Communication, 8(2-3), 223-248.

Iftikhar Ahmad Khokhar (2017):Testing Major Linguistic Politeness Theories against the Marital Relationships of Bilingual (Urdu and Punjabi) Speaking Pakistani Couples, Linguistics and Literature Review3(2): 29-46.

Kecskes, I. (2013). Intercultural pragmatics. Oxford University Press.

Kousar, S. (2015). Politeness orientation in social hierarchies in Urdu. International Journal of Society, Culture \& Language, 3(2), 85-96.

Lin, H. H. (2005). Contextualizing linguistic politeness in Chinese-A socio-pragmatic approach with examples from persuasive sales talk in Taiwan Mandarin (Doctoral dissertation), The Ohio State University.

Liu, A. (2009). She is kind of clueless but cute: Politeness in sales communication in Hong Kong. LCOM Papers, 1, 81-97

Mohammad Aliakbari \& Rezvan Moalemi. (2015). Variation of Politeness Strategies among the Iranian Students. Theory and Practice in Language Studies, 5(5), 981-988.

Ogiermann, E. (2009). Politeness and in-directness across cultures: A comparison of English, German, Polish and Russian requests. Journal of Politeness Research, 5, 189-216

Rahayuningsih, D., Saleh, M., \& Fitriati, S. W. (2020). The realization of politeness strategies in EFL teacher-students classroom interaction. English Education Journal, 10(1), 85-93.

Reiter, R. M., \& Bou-Franch, P. (2017). (Im) politeness in service encounters. In the Palgrave Handbook of Linguistic (Im) politeness (pp. 661-687). Palgrave Macmillan, London.

Rustandi, A. (2018). THE UNIVERSITY STUDENTS 'EXPRESSIONS OF POLITENESS STRATEGIES ON STUDENTS' REQUEST IN CLASSROOM INTERACTION IN INDONESIAN CONTEXT. Forum Penelitian: ISSN

Tracy, K. (2017). Facework and (im) politeness in political exchanges. In the Palgrave handbook of linguistic (im) politeness (pp. 739-758). Palgrave Macmillan, London.

Traverso, V. 2006. Aspects of polite behaviour in French and Syrian service encounters: A data-based comparative study. Journal of Politeness Research, 2, $105-122$ 